\title{
A holistic framework for developing excellent academic practice
}

\author{
Ruth Pickford \\ Leeds Beckett University
}

\begin{abstract}
This article outlines an original and practical framework that synoptically integrates the factors underpinning a strategic approach to developing excellent academic practice (DEAP) within an institution.

It considers recent developments driving development of 'excellence' in academic practice and describes a practical model - based on the requirements of the sector, the needs of institutions and the perspectives and goals of staff - that can be used to meet the desires of the various stakeholders.

The framework's philosophy is that outcomes depend upon three factors: individual colleagues' attributes at different stages of their career; the opportunities provided at each career stage to develop academic practice; and the agency of the colleague and the institution to engage with one another behaviourally, emotionally and/or cognitively to align these attributes and opportunities.

The framework is likely to be of practical use to all staff engaged in developing their own or others' academic practice, while at the same time offering a theoretical framework for scholarship.
\end{abstract}

\section{Keywords: Opportunities, Engagement, Academic Practice, Excellence.}

\section{Introduction}

Good academic practice and the notion of excellence are currently at the heart of national and international higher education (HE) policy discourse. In the UK, in response to expectation, $\mathrm{HE}$ providers are increasingly seeking to demonstrate their commitment to excellence - in teaching and learning, in providing value for money for students, parents and taxpayers (Office for Students, 2018) and in offering an academic service to the wider community through research, enterprise and knowledge exchange. Internationally, references to excellent academic practices are found in most nations' policy documents, yet none has, to date, developed an accepted definition of excellent academic practice. Nevertheless, national and international frameworks and league tables - that purport to measure and compare the quality of academic practices of different institutions - will inevitably become an ever more significant feature of the international HE landscape. This, in turn, will have increasing impact upon institutional strategic plans and upon the specification of institutional Key Performance Indicators, staff awards, staff recruitment and schemes for staff recognition and promotion. UK institutions are currently developing institutional approaches and frameworks to align their academic practices with the developing TEF (Pickford, 2018), the revised Research Excellence Framework (REF), the 
emergent Knowledge Exchange Framework (KEF), the Office for Students' (OfS) requirements for civic engagement and the various metrics that contribute to national and international league tables. It is timely to adopt a holistic perspective and consider what is necessary to develop excellent academic practice and what institutional action is required to achieve this.

Interventions targeted at improving individuals' practices, enhancing organisational learning or achieving institutional outcomes developed in isolation often fail to bring about long-term, sustainable changes in organisational culture. There is a growing imperative for the sector and for institutions to think synoptically about the development of excellent academic practice to enable development of sustainable institutional strategies. The aligned approach proposed here will support consistency within, across and between institutions. While reference is made in the paper to the UK context, the proposal draws upon significant international scholarship and, as nations globally are adopting similar strategic approaches, it is argued that the blueprint has the potential for a global reach.

\section{The context of developing excellent academic practice}

How academic practice is perceived in a university depends on a combination of factors, including externally imposed metrics and criteria, the institution's self-identified mission, each discipline's approach to research and education, student perspectives and the perspectives and goals of those who teach and/or support learning. These different orientations determine - within each institution, department and course/programme - how excellent academic practice comes to be defined. In order to develop effective academic practice, universities must first identify and then manage these various orientations. The most successful higher education institutions (HEls) will go further and exploit them to their advantage. The challenge for many institutions in seeking to develop 'excellent' academic practice is that there is currently no consensus in the sector about the differences between proficient, meritworthy and excellent academic practice, despite the use of 'excellence' in an assortment of emerging frameworks and awards. In the UK, the requirements of the OfS, relating to access, success and progress (Office for Students, 2018), the introduction of the Teaching Excellence Framework (TEF), the launch of the new Research Excellence Framework (REF) and the growing array of high-profile awards for excellence have sought to provide qualitative and quantitative criteria for excellence. However, these external recognition systems use an uncalibrated variety of metrics and criteria. Brew (2007, p.84) observed: "Differing perspectives on excellence create a range of different and sometimes conflicting demands on higher education institutions". At best, the many (and multiplying!) excellence criteria are unmanageable and difficult to integrate into internal strategies and, at worst, they leave institutions paralysed in an avalanche of variously-nuanced lists of quality indicators. Furthermore, and perhaps more importantly, there is little attempt by the sector to argue that these criteria built on transferable educational principles, are developed from theoretical models or even supported by robust evidence of positive impact on outcomes. For example, Gunn and Fisk (2013, p. 47) observed: "What is demonstrated clearly by teaching excellence awards is that individual excellence has primarily been defined by initiatives and individuals which have come to be recognised as excellent, rather than as having been identified through theoretically robust, systematic or strategic models".

In order to develop excellent academic practice, it is necessary for institutional leaders to understand what constitutes proficiency, merit and excellence; then, to have a clear strategy 
to move through proficiency to excellence; and, finally, to provide appropriate opportunities for staff to develop their own and others' academic practice. A successful, sustainable, institutional strategy for developing excellent academic practice needs to be cognizant of four factors that I define as:

1. the diversity of staff roles, goals and orientations;

2. the current national and international imperatives relating to academic practice;

3. the need to provide supported opportunities for staff at different career stages to develop their own academic practice, to enhance practices and to achieve required outcomes;

4. the requirement for a successful strategy to develop excellent academic practice to align orientations, opportunities and imperatives underpinned by institutional infrastructure, policies and systems.

The following sections address each of these factors in turn.

\section{Differing academic practitioner roles, goals, orientations, and ways of engaging}

Central to the framework presented in this paper is the thesis that engagement is an individually-owned and personal concept (Kahn, 1990). Engagement is a psychological state and is "a distinct and unique construct consisting of cognitive, emotional and behavioural components" (Saks, 2006). It follows, therefore, that institutional strategies - and development and recognition policies that treat staff as a homogenous group - are likely to be less successful than those that acknowledge that a diverse staff body will engage differently and for different reasons. Though universities cannot effectively build engagement at a group level, they must focus interventions at the individual level. Moreover, Burton, Buchan and Tarleton (2015) argue that individuals can be engaged with different things at different times, that some engagement may actually be detrimental to organisational interests (if it does not align with organisational intents) and that the seeds of engagement are sown at a deep level of consciousness. As individuals' psychological states vary, so too will their approach to engagement in academic practice and their agency. The ways that a colleague will engage with her/his work will be determined, inter alia, by their context, role, discipline, perspective, orientation and goals and, according to Gordon (2000), by the desire to minimise threat and maximise reward. Expectations of the purpose of universities differ widely, accordingly to the stakeholder. Related to these expectations are diverse orientations towards 'academic practice' (Land, 2004) that colour how each group defines excellence.

Recognising that research and teaching and administration are equally important but discrete aspects of academic practice enables us to frame developing excellent academic practice through the interaction of staff with different strengths and assets. This challenges the uncomfortable tripartite research-teaching-administration divisions, acknowledging that all of what we do as researchers, teachers and professionals plays a role in developing academic practice and that, rather than exclusively focusing on individual excellence in any one area, it would be better were we to embrace this as collective expertise. Furthermore, were we to appreciate a) that there is likely to be a spectrum of personal drivers - spanning 
behavioural, emotional and cognitive engagement - in any one disciplinary academic tribe (Becher, 1989) and b) that such varied stimuli, if harnessed, can make positive individual contributions to a rich community of academic practice, then we should have a firm conceptual base from which to develop organisational learning and, in consequence, achieve institutional excellence.

\section{Current imperatives relating to excellent practice}

Alongside the notion of agency, it is necessary to consider, in turn, the constituent elements of practices associated with a continuing focus on fostering excellent academic practice, enhancement and outcomes.

\section{Practice: academic proficiency}

There is an ethical, financial, quality-assurance and reputational imperative on HEls to ensure that staff are competent academic practitioners - capable of: contributing positively to courses; producing and using up-to-date research, methods, technologies and techniques; engaging with students; and providing students with the information, support and skills to be successful.

\section{Enhancement: formal and informal academic leadership}

To sustain high-quality academic practice, any HEI needs to develop the expertise required to enhance the personal impact of its academic practitioners. Whilst central academic development departments are commonly tasked with providing this expertise, a strategy that augments this expertise - through engaging the wider university community in supporting and developing the academic practice of others - will sustainably increase organisational effectiveness.

Outcomes: organisational impact

There is an increasing global focus on enhancing academic practice and students' university experiences and, in particular, on excellent teaching. A series of proxy measures is being introduced and, in the increasingly competitive UK market, institutions are now routinely displaying on their websites and in prospectuses a plethora of badges, accreditations, awards and achievements to demonstrate that their academic practice is esteemed nationally, if not internationally. In the UK, these 'badges of honour' include: placement in national league tables, Teaching Excellence and Student Outcomes Framework (TEF) and REF awards, high-profile civic engagements, personal case studies, innovative institutionwide approaches and professional recognition at individual, team and institutional level through, for example, National Teaching Fellowships (NTFs), and Times Higher Awards (THEAs).

Institutional success in achieving these indicators of esteem is dependent upon the seriousness of an institution's interest in doing so - largely determined by whether these affirmations are judged to strengthen the institutional 'brand' and the institution's ability to develop 'excellent' academic practice - through engaging their staff in enhancing both their individual impact and their impact on the academic practice of others. 


\section{Providing opportunities for development of academic practice}

If we wish to leverage staff engagement in developing excellent academic practice, we need, as universities, to provide the engagement opportunities, conditions and systems of recognition and reward that align with both different career stages and with the array of individual orientations and goals of different academic communities.

HEls need to provide these appropriate and necessary conditions through a systematic, integrated framework that provides opportunities for staff to engage behaviourally, emotionally and cognitively. This must be manifested in opportunities for focused creation of knowledge and application of knowledge - by means of tailored development environments and of developmental activities. Figure 1, which builds on earlier work on orientation of staff and student engagement with $\mathrm{HE}$, demonstrates these conditions in practice (Pickford and Brown, 2013; Pickford, 2016; Pickford, 2018).

Figure 1: Integrated framework for development of academic practice aligned with staff orientations

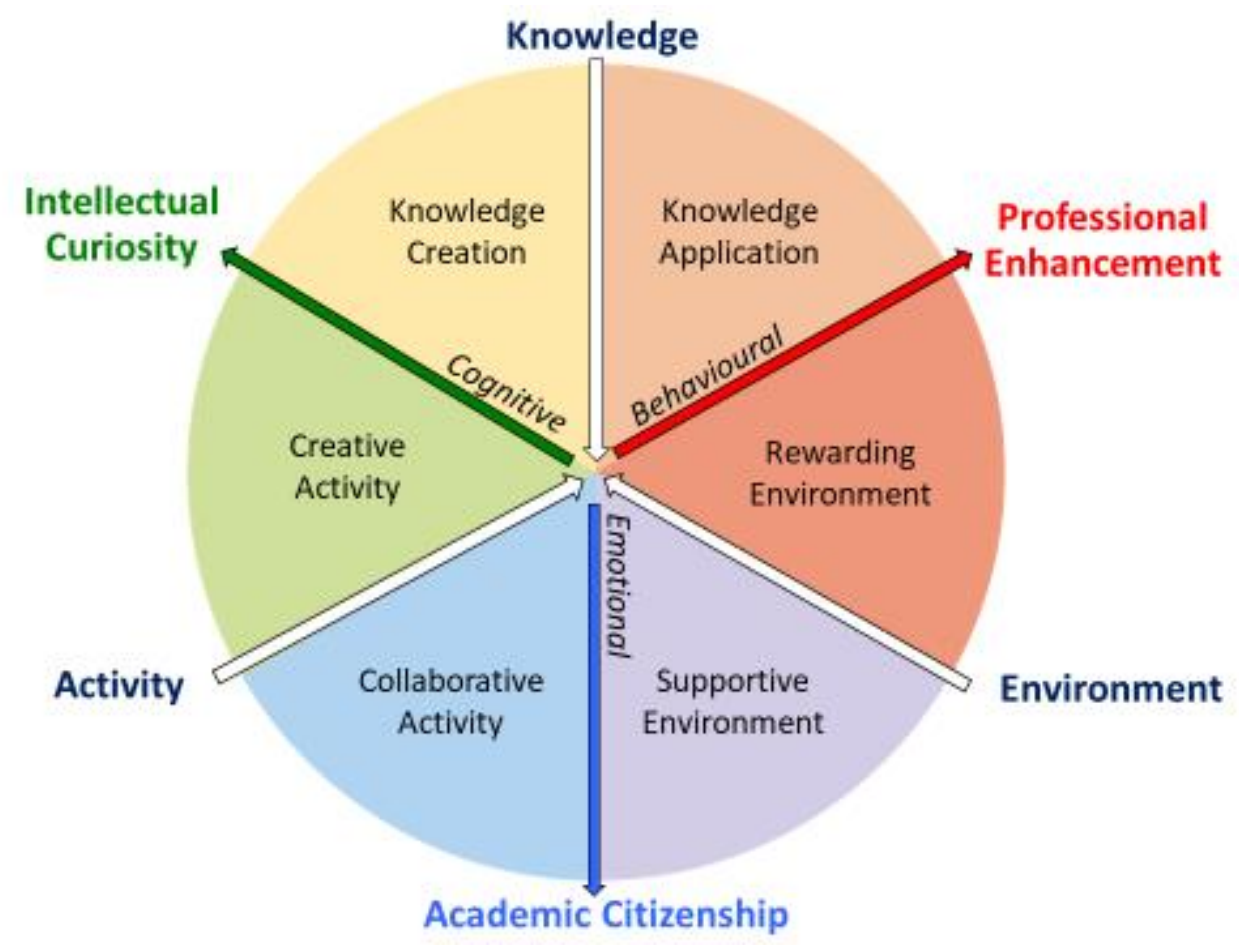

This model - focusing as it does on the creation and application of knowledge, on a rewarding and supportive development environment and on collaborative and creative developmental activities - can form (and indeed does at the author's home institution) the basis of an institutional strategy to provide opportunities to meet the collective goals of a diverse body of colleagues. Colleagues primarily motivated by professional enhancement achieved through improving their performance against key performance indicators or by, for example, building their professional reputation - may especially value opportunities to engage in enhancement initiatives that evaluate and apply evidence or with CPD opportunities that are situated in a rewarding development environment. Those motivated by a sense of academic citizenship to engage with others and support and guide colleagues may particularly value opportunities to collaborate as a member of an academic community in a supportive development environment. Colleagues motivated by intellectual curiosity to research or to make an original contribution to academic practice may value opportunities to 
contribute to the creation of knowledge or to pilot innovations through creative developmental activity.

In order to engage staff fully, it is necessary to consider aligning opportunities with the different career stages of academic practitioners and to link opportunities to their key motivators. All staff should be provided with opportunities to engage: in reflective practice, in professional development and in research-informed practice; with personalised support, with a vibrant academic community and with new and emerging approaches. Beyond this, staff need to be offered opportunities to engage formally, socially and intellectually with other staff to drive development of academic practice. These opportunities could include working in teams to enhance courses, development of colleagues across the institution, peer support, formal collaborations, acting as institutional change agents and engaging in and sharing research.

\section{A framework aligning staff orientations with current imperatives relating to development of academic practice}

By aligning opportunities with organisational imperatives and with staff orientations, it is therefore possible to develop a holistic blueprint - which appeals to staff, whatever their orientation - for developing excellent academic practice which appeals to staff.

Figure 2: The Developing Excellent Academic Practice Framework

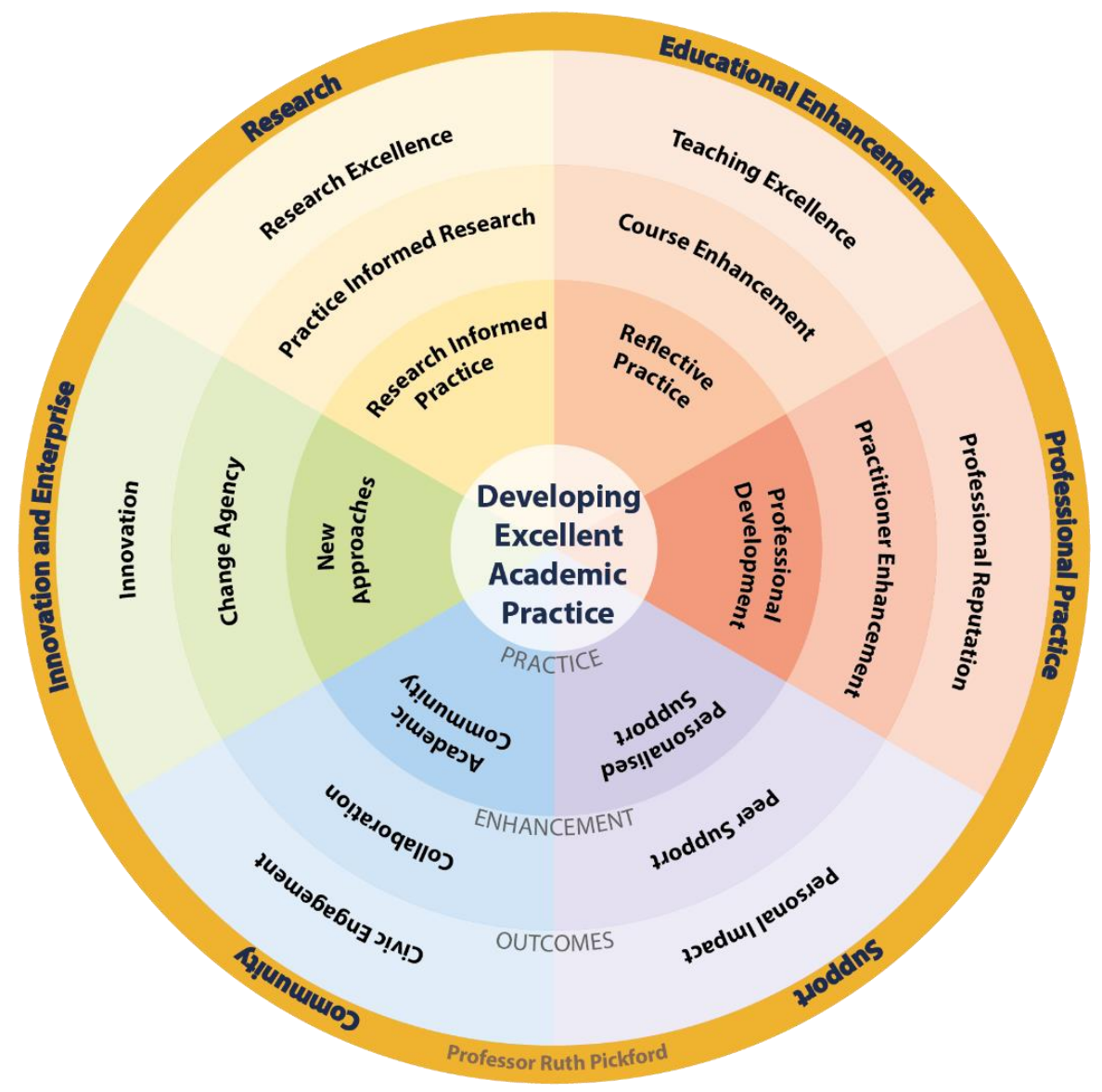


The proposed framework (Figure 2) holistically aligns these elements of academic practice. Using this model, it is possible to design, manage, monitor and evaluate a strategy to develop excellent academic practice.

The proposed blueprint, presented as a well-received keynote at the 2017 SEDA Conference (Pickford, 2017), aligns six related elements of excellent academic practice:

- Educational Enhancement

- Professional Practice

- Support

- Community

- Innovation and Enterprise

- Research

These interdependent elements of academic practice identify the opportunities required at different career stages to progress from excellent individual practice to excellent organisational outcomes. The six streams align to colleagues' specific orientations towards their academic practice and towards the ways individuals look to engage.

Aligned agency, opportunities and imperatives are considered in turn:

\section{Educational Enhancement (orange in model)}

Enhancement of teaching excellence and student outcomes (TEF) - at course/programme, subject and institutional levels - can be fostered through a strategy that a) provides optimum conditions for all academic practitioners to engage in reflective practice relating to their personal impact on courses and b) subsequently engages these reflective practitioners in planning evidence-informed enhancements to their own courses and to other courses in the institution.

\section{Professional Practice (red in model)}

Increasing professional reputation through international and national recognition of individual, group and institutional excellence can be achieved by a) celebrating all practitioners who increase their reputation through formal professional development opportunities and b) rewarding those who subsequently use their learning to enhance the CPD of colleagues across the institution.

\section{Support (lilac in model)}

Supporting colleagues to become academic practitioners with personal impact can be fostered by a) providing accessible, personalised support for all and b) developing a supportive environment in which colleagues are encouraged to support and have positive impact on others.

\section{Community (blue in model)}

Providing a public service - through extensive and high-profile civic engagement, consultancy and events - can be achieved by developing such a culture that all staff have 
the opportunity to belong to a community of academic practice, to participate in it and collaborate as a member of it.

\section{Innovation and Enterprise (green in model)}

Innovation can be fostered by introducing all colleagues to new and emerging approaches, encouraging them to experiment in a safe environment and subsequently empowering them to have, as change agents, creative impact across and beyond the institution.

\section{Research (yellow in model)}

Enhancement of research excellence (REF) can be fostered a) through a strategy that requires research-informed practice by all and $b$ ) by encouraging academic practitioners to engage in research that has positive impact upon understanding within, across and beyond the institution.

\section{Discussion}

This paper proposes how current imperatives can successfully be aligned with staff agency and motivation to engage in development of academic practice through provision of tailored opportunities. The framework can demonstrably be used to achieve a positive impact through the implementation of pragmatic and measurable activities to develop and demonstrate excellent academic practice.

Adopting a holistic approach to developing and rewarding academic practice also offers the opportunity to recognise those activities that lie on the intersections between teaching, research, administration and academic citizenship and to resolve the tensions that are inherent in managing these different strands of academic activity. Many valuable academic activities are unrecognised (Blackmore and Kandiko, 2011). For example, Clegg and Rowland (2010) argue that kindness and concern for lay normativity are commonplace, but that - because they cannot be regulated or prescribed - they go unremarked. Likewise, Brew (2011) observes that, in the context of the national research assessments that are commonplace in many countries, a misguided belief exists that present-day disciplinary research productivity is all that matters, resulting in academics' being increasingly discouraged from researching the teaching of their discipline and instructed to concentrate on disciplinary research. She argues, however, that, in twenty-first century society, the capacity to adapt and change teaching and learning in continually-shifting circumstances is critical for the future of any discipline and that without it, the capacity of the discipline to reproduce itself will be undermined. A truly integrated approach to holistic development of academic practice that embraces these intersections and rejects the artificial separations between emotion, reason and ambition will, I argue, sustain these critical activities.

The lack of a recognised definition of academic excellence that speaks to a whole university community will inevitably lead to a failure, to the detriment of the institution, to exploit individual expertise - that of all staff - which would be of benefit to it. Such a deficiency presents many HEls with inherent problems in aligning strategies with reward and recognition schemes. For example, Gunn and Fisk (op.cit.), concluded from their literature review that a taxonomy of teaching excellence that allows for different orientations towards teaching - as expressed by different role profiles over the stages of an academic career would be useful. A pragmatic response is for institutions to take ownership of the concept of 
excellent academic practice and to create a sustainable, research-informed and evidencebased blueprint for developing it. A shared, robust approach will empower institutions to respond, rather than react, to continuing changes in external requirements and metrics, while at the same time supporting individual academic practitioners to enhance their practice in meaningful ways. The framework outlined here builds upon staff motivation to underpin a professional development strategy that enables and empowers colleagues to achieve successful outcomes for themselves and for their universities. It can also enable consistent communication between different areas of a university and support internal and external collaboration.

The framework has been developed specifically and pragmatically for personal, team and institutional enhancement of academic practice. Had this approach been adopted merely to align with the series of proxy measures and criteria currently being used in the sector to measure 'excellence' it would have been ill-considered. In a volatile sector, the current criteria are liable to change and new measures will almost certainly be introduced rapidly. More importantly, however, an institution-wide holistic approach to the development of excellent academic practice, as described and practised here, requires visible high-level support from a university's executive, deans and directors. An approach developed principally to achieve short-term success, without its roots in research and evidence-based practice, would be of little interest to academic practitioners and of limited value to a university executive focused on developing long-term, sustainable strategies that should sit above the constant stream of new government initiatives and sector requirements. However, starting from a consideration of the diverse orientations in any community of academic practice, and building upon the elements of research-informed and evidence-based approaches, developmental activities and development environments that align with these different orientations can provide a basis for a sustainable holistic approach that can underpin successful institutional outcomes. If we set out to improve performance against the plethora of external criteria currently being used in the sector to judge excellence, then we may reach the same point, but in a less coherent way. Success in esteem measures can be achieved only if staff are engaged. It follows that a framework to maximise the chances of success against these external measures of prestige necessarily requires development of academic practice at personal and organisational levels, aligned with appropriate engagement opportunities (relating to educational enhancement, professional practice, support, community, innovation and enterprise, and research) that, in turn, align with the personal orientations and goals of staff.

\section{Conclusion, recommendations and further work}

Based upon the experiences of the author's university, institutions could use this blueprint most effectively as a tool for planning, analysis, evaluation and recognition. University executives, pro-vice-chancellors (learning and teaching), academic development directorates, academic services, promotion panels and deans can use the framework systematically to design, plan, manage, monitor, evaluate and enhance academic practice. It can also be used developmentally to identify specific elements of academic practice that are meeting or failing to meet requirements.

This framework can be applied across a range of contexts, but will likely see more immediate positive outcomes if it has: 
- senior level leadership and support;

- a high institutional profile;

- central, institutional-level coordination;

- an aligned institutional development programme;

- clear alignment with institutional initiatives, policies and strategies.

It is recommended that further work could usefully explore:

a. the potential for the framework to embrace an integrated approach to management, administration, teaching, research, enterprise and knowledge exchange, forming the basis for a higher education blueprint that could be used to support development of integrated holistic institutional strategic plans. Specifically, there is potential to extend the framework to include research outputs and research impact as well as aligned opportunities to underpin organisational sustainability.

b. how this framework could be aligned with institutional approaches to student access, success and progress and to student engagement (Pickford, 2016) and with current metrics relating to teaching excellence and student outcomes to form the basis for a holistic blueprint to enhance the experiences of students and colleagues. Since Gunn and Fisk (op.cit.) suggest that the overriding requirement is to develop a shared repertoire (a taxonomy) in relation to teaching and teacher excellence, this approach can be useful in building a systematic map of what activities, approaches and dispositions are required to achieve excellence. This is a view supported by Little and Locke (2011, p.19): "A teaching mission necessarily embraces both a concern for teaching and a concern for the end product of the teaching process that is: the student learning experience."

c. how this framework could be used - as the basis of institutional strategies and recognition and reward policies - to map synoptically the criteria of new frameworks, standards and awards as they emerge and to structure the work and evaluate the impact of academic development departments.

Within the author's institution, the framework is being used in a number of ways:

- The University's Centre for Learning and Teaching (CLT) is structured around this framework, with team members' job titles and responsibilities aligning with the six aspects of developing excellent academic practice;

- An impact-evaluation framework, with eighteen quantitative and qualitative metrics based on the eighteen elements of the model, is used annually to evaluate the performance and impact of CLT at an accountability meeting with the University's Executive Team;

- The framework is informing development of an integrated institutional academic promotions framework;

- The framework is supporting an integrated approach to CPD, bringing together development opportunities supported by People and Organisational Development, 
The Graduate School and CLT, to provide colleagues with informed choices relating to academic career development;

- Used in conjunction with The Blueprint for Teaching Excellence (Pickford, 2018), the framework underpins the institution's Education Strategy and the development of a cross-institutional 'Learning Pathway'.

Though this work continues, early evidence indicates increased colleague engagement and improved organisational outcomes across the six domains.

\section{Reference list}

Becher, T. (1989) Academic tribes and territories: Intellectual enquiry and the cultures of disciplines. Buckingham: Open University Press/SRHE. ISBN. 978-0335206278.

Blackmore, P. and Kandiko, C.B. (2011) 'Motivation in academic life: a prestige economy.' Research in Post-Compulsory Education, 16(4), 399-411. Available at: https://www.tandfonline.com/doi/abs/10.1080/13596748.2011.626971 (Accessed: 29 October 2018).

Brew, A. (2007) 'Integrating research and teaching: Understanding excellence.' In: Skelton, A. (ed.) International Perspectives on Teaching Excellence in Higher Education: Improving Knowledge and Practice. Abingdon, Oxon: Routledge. ISBN. 978-1138973206.

Brew, A. (2011) 'Higher education research and the scholarship of teaching and learning: The pursuit of excellence.' International Journal for the Scholarship of Teaching and Learning, 5(2), 3. Available at: https://digitalcommons.georgiasouthern.edu/ij-sotl/vol5/iss2/3/ (Accessed: 29 October 2018).

Burton, C., Buchan, L. and Tarleton, R. (2015) Engagement and wellbeing: An integrated model, Designed4Success. Available at: https://engageforsuccess.org/wpcontent/uploads/2015/12/Engagement-and-Wellbeing-Dec-15.pdf (Accessed: 29 October 2018).

Clegg, S. and Rowland, S. (2010) 'Kindness in pedagogical practice and academic life.' British Journal of Sociology of Education, 31(6), 719-735. Available at: https://www.tandfonline.com/doi/full/10.1080/01425692.2010.515102 (Accessed: 29 October 2018).

Gordon, E. (2000) Integrative neuroscience: Bringing together biological, psychological and clinical models of the human brain. Singapore: Harwood Academic Publishers. ISBN. 9789058230553.

Gunn, V. and Fisk, A. (2013) Considering teaching excellence in higher education: 20072013: A literature review since the CHERI Report 2007. Project Report. York: Higher Education Academy. Available at: http://eprints.gla.ac.uk/87987/1/87987.pdf (Accessed: 29 October 2018). 
Kahn, W.A. (1990) 'Psychological conditions of personal engagement and disengagement at work.' Academy of Management Journal, 33(4), 692-724. Available at:

https://journals.aom.org/doi/abs/10.5465/256287 (Accessed: 29 October 2018).

Land, R. (2004) Educational development: Discourse, identity and practice. Maidenhead. Society for Research into Higher Education and Open University Press. ISBN. 9780335213283.

Little, B. and Locke, W. (2011) 'Conceptions of excellence in teaching and learning and implications for future policy and practice.' In: Rostan and Vaira, M. (eds.) Questioning Excellence in Higher Education: Policies, Experiences and Challenges in National and Comparative Perspective. Rotterdam: Sense Publishers. ISBN. 978-9460916403.

Office for Students (2018) Office for Students Strategy 2018 to 2021. OfS,18, 30 ${ }^{\text {th }}$ April 2018. Available at: https://www.officeforstudents.org.uk/publications/office-for-studentsstrategy-2018-to-2021/ (Accessed: 29 October 2018).

Pickford, R. (2016) 'Student engagement: Body, mind and heart - a proposal for an embedded multi-dimensional student engagement framework.' Journal of Perspectives in Applied Academic Practice. 4 (2). ISSN 2051-9788. DOI: 10.14297/jpaap.v4i2.198. Available at: https://jpaap.napier.ac.uk/index.php/JPAAP/article/view/198/pdf (Accessed: 29 October 2018).

Pickford, R. (2017) Reinventing the wheel: A blueprint for supporting course teams to develop teaching excellence. Opening Keynote Address, $22^{\text {nd }}$ Annual SEDA Conference, Cardiff, $16^{\text {th }}-17^{\text {th }}$ November 2017. Slides available at:

https://www.slideshare.net/seda_uk_/ruth-pickford (Accessed: 29 October 2018).

Pickford, R. (2018) 'A blueprint for teaching excellence.' Journal of Perspectives in Applied Academic Practice, 6(1). Available at:

https://jpaap.napier.ac.uk/index.php/JPAAP/article/view/299/435 (Accessed: 29 October 2018).

Pickford, R. and Brown, S. (2013) 'Themes, orientations, synergies and a shared agenda: The first 20 years of the SEDA series of books.' Innovations in Education and Teaching International, 50(4). Available at:

https://www.tandfonline.com/doi/full/10.1080/14703297.2013.839390 (Accessed: 29 October 2018).

Saks, A.M. (2006) 'Antecedents and consequences of employee engagement.' Journal of Managerial Psychology, 21(7), 600-619. Available at:

https://www.emeraldinsight.com/doi/full/10.1108/02683940610690169 (Accessed: 29

October 2018). 